\title{
REPLACEMENT OF POSTERIOR MISSING TEETH WITH PORCELAIN FUSED TO METAL (PFM) BRIDGE
}

\author{
Eni Rahmi ${ }^{1}$
}

${ }^{1}$ Staff pengajar Fakultas Kedokteran Gigi Universitas Andalas

\begin{abstract}
Background: Porcelain fused to metal (PFM) bridge is the most of treatment that commonly used as a fixed partial dentures. One of the indication for PFM bridge is to replacing the loss of posterior teeth. This case report discussed about the treatment of posterior missing teeth with PFM bridge. Objective: to explain the clinical procedures of PFM bridges to treat the patient with posterior missing teeth. Case report: A 29-years old woman came to prosthodontic clinic in Faculty of Dentistry University of Padjadjaran with chief complaint of right maxillary posterior missing teeth. The treatment planning that have been choosen for this case was the porcelain fused to metal bridge due this excellent characteristic of resistence to mastication force compared with other types of bridge such as all ceramic or all acrylic bridge. Beside that, the aesthetic achievement of this kind of bridges is more excellent than all metal bridges. Disscussion: A spatial analysis, calculation the number of abutment against which used, and selected design bridge very determine the success of this treatment. In addition to that, the clinical procedures consisting of abutment teeth preparation, an accurate impression, and appropriate cementation were needed to get the satisfactory result. Conclusions: The porcelain fused to metal bridge is a appropriate option for posterior missing teeth treatment that fullfil satisfactorical biomechanical and esthetic factors.
\end{abstract}

Key words: porcelain fused to metal bridge, posterior missing teeth

Affiliasi penulis: ${ }^{1}$ Staff Pengajar Fakultas

Kedokteran Gigi Universitas Andalas

Korespondensi: Eni Rahmi

email: enirahmi@yahoo.com

\section{PENDAHULUAN}

Kehilangan satu atau lebih gigi permanen dapat berpengaruh pada penampilan seseorang dan kesehatan secara keseluruhan yang akan berdampak pada kualitas hidupnya. Kondisi ini sangat mempengaruhi jaringan mulut khususnya fungsi sistem mastikasi dan estetik. Dampak kehilangan gigi anterior lebih terlihat pada fungsi estetik dan fonetik, sedangkan kehilangan gigi posterior akan mempengaruhi fungsi mastikasi. Hilangnya gigi ini jika tidak segera diganti akan menyebabkan perubahan-perubahan dalam rongga mulut seperti terjadi resorpsi tulang alveolar, migrasi dan drifting gigi sebelahnya, serta ekstrusi gigi antagonis. ${ }^{1,2}$ Love dan Adam menyatakan bahwa biasanya pergerakan gigi ke arah daerah tidak bergigi di sebelahnya terjadi 5 tahun setelah pencabutan gigi. Penggunaan gigitiruan jembatan masih menjadi pilihan pasien untuk menggantikan kehilangan satu atau dua gigi karena faktor kenyamanan, estetik, dan biaya yang relatif lebih murah dibandingkan implant gigi. ${ }^{3}$ 
Meskipun perkembangan gigitiruan jembatan sangat cepat, yang terbukti dengan berkembangnya berbagai macam gigitiruan jembatan seperti all ceramic bridge dan adhesive bridge, gigitiruan jembatan metal porselen masih menjadi pilihan karena secara klinis dapat digunakan dalam jangka waktu lama dan bersifat biokompatibel. Karlsson (1986) melaporkan 93\% angka keberhasilan penggunaan jembatan metal porselen dalam jangka waktu 10 tahun. Palmqvist dan Swartz (1993) melaporkan tingkat keberhasilan penggunaan gigitiruan ini selama 18 - 23 tahun sekitar $79 \%$. Kegagalan yang ditemukan biasanya adalah fraktur lapisan porselen. ${ }^{4}$

Jenis jembatan ini digunakan secara luas untuk menggantikan kehilangan dalam jumlah yang banyak terutama gigi posterior. $^{4-6}$ Keuntungan gigitiruan jembatan metal porselen antara lain penampilan struktur yang dapat diprediksi, estetis yang lebih baik dan biaya yang relatif terjangkau. ${ }^{4}$ Jembatan ini menggabungkan kekuatan dan keakuratan dari metal dan sifat estetik dari porselen. ${ }^{6}$

Tipe jembatan ini juga memiliki kekurangan, antara lain terjadi pigmentasi gingival berwarna biru keabu-abuan akibat pengaruh alloy logam $\mathrm{Ni}-\mathrm{Cr}$ yang menjadi koping. Hal ini terjadi karena kondisi lingkungan mulut sehingga terjadi korosi yang menyebabkan terlepasnya ion-ion logam. Schmaltz dan Garhammer melaporkan bahwa ion logam yang dilepaskan dari gigitiruan metal porselen melalui proses korosi menyebabkan reaksi yang luas pada gingival. Berdasarkan hasil penelitian Ristic Secara analisis histopatologis, diskolorisasi gingival diduga berhubungan dengan deposisi mikropartikel logam pada jaringan gingival. Penelitian ini sejalan dengan penelitian Wataha yang melaporkan ion logam seperti as $\mathrm{Ni}^{3+}$ dan $\mathrm{Cr}^{+}$yang dilepaskan dapat mengakibatkan perubahan sifat fibriblast gingival termasuk metabolism dan proliferasi, serta peningkatan level mediator inflamasi. Hasil yang berbeda dilaporkan oleh MinTian (2016) yaitu tidak terdapat ion $\mathrm{Ni}$ dan $\mathrm{Cr}$ pada gusi yang mengalami pigmentasi. $^{7}$

\section{LAPORAN KASUS}

Seorang pasien wanita usia 29 tahun datang ke klinik Prostodonsia FKG Universitas Padjadjaran dengan keluhan telah kehilangan gigi geraham atas lebih kurang 8 tahun yang lalu. Pasien belum pernah menggunakan gigitiruan sebelumnya dan ingin dibuatkan gigitiruan yang cekat demi kenyamanan dan pengunyahan. 
Dari pemeriksaan intra oral diketahui pasien kehilangan gigi 15, 25, 27, 47 dan 48. Karies media terdapat dipermukaan oklusal gigi 26 dan Gigi 16, 2628 mengalami pergerakan sehingga ruangan di regio gigi 15,25 , dan 27 mengalami penyempitan ruangan. Gigi 26 mengalami mesial drifting sekitar 6 derajat. (Gambar 1) Pada gigi 14, 24, 45, 46, dan bucal pit 37 terdapat tambalan klas 1 amalgam, sedangkan pada gigi 37 terdapat tambalan klas 1 komposit.

Pemeriksaan radiografis dari rongent panoramik menunjukkan gigi 12 dan 21 post perawatan endodontik dan telah dipasangkan gigitiruan mahkota pasak. Rasio mahkota akar gigi 14, dan 24 adalah $1: 2$, sedangkan rasio mahkota akar gigi 16, 26, dan 28 adalah $2: 3$. Jaringan periodontal di sekitar gigi 16 , 14, 24, 26, dan 28 terlihat normal serta tidak terdapat kelainan periapikal pada gigi-gigi tersebut. (Gambar 2)

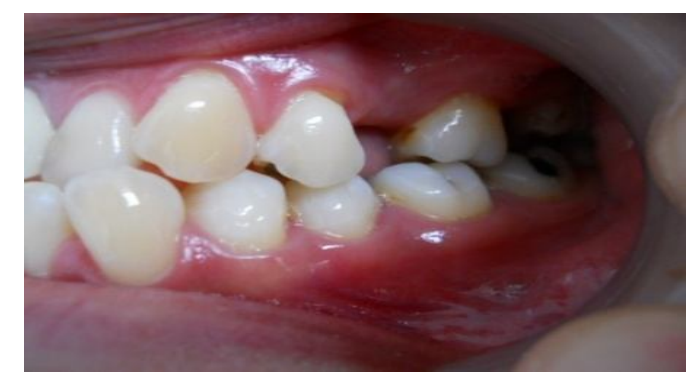

Gambar 1. Gambaran klinis kehilangan gigi 25 dan 27.

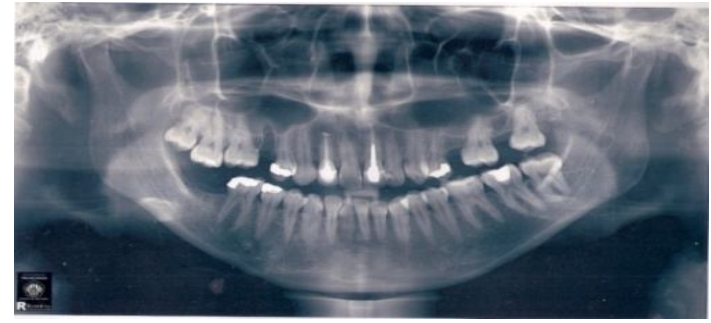

Gambar 2. Gambaran radiologis panoramic pasien

Berdasarkan hasil anamnesis, pemeriksaan klinis, dan radiologis, rencana perawatan yang akan dilakukan adalah pembuatan gigitiruan adhesive bridge pada regio gigi 14,15 , dan 16 serta porcelain fused to metal bridge pada regio gigi 24, 25, 26, 27, dan 28 . Desain jembatan PFM adalah fixedmovable bridge, abutment pada gigi 24 , 26, dan 28, retainer berupa mahkota jaket metal porselen pada gigi 24,26 dan inlay pada oklusal gigi 28 , modified ridge lap pontic pada gigi 25 dan conical pontic pada gigi 27 , serta konektor rigid antara 24 dan 25 dan nonrigid pada 27 dan 28.

\section{Penatalaksanaan Kasus}

Setelah dilakukan preprosthetic mouth preparation berupa skeling dan perbaikan tambalan yang ada, perawatan dimulai dengan melakukan preparasi gigi abutment. Pengurangan jaringan di permukaan bukal dan palatal gigi 24 dan 26 dilakukan dengan flat end tapering bur sebanyak 1,5 mm, sedangkan pada bagian oklusal sebanyak $2 \mathrm{~mm}$. Akhiran 
servikal preparasi berbentuk shoulder selebar $1 \mathrm{~mm}$ dibuat dengan menggunakan flat end tapering bur. Preparasi inlay dilakukan pada permukaan oklusal gigi 28 dengan menggunakan cilindris bur. ${ }^{5,6,9}$

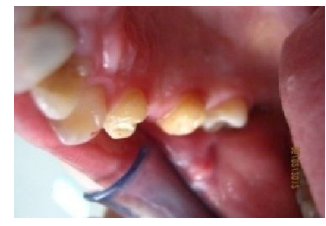

A

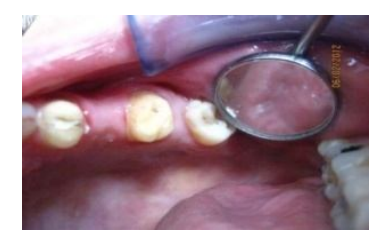

B
Gambar 3. Preparasi gigi dilihat dari palatal (A) dan oklusal (B)

Setelah preparasi selesai, dilakukan pencetakan dengan double impression technique menggunakan bahan cetak polyvinyl siloxan. Tahap selanjutnya dilakukan bite registrasion dan pemasangan jembatan sementara. Model kerja dikirim ke laboratorium untuk pembuatan koping logam. Uji coba koping logam dilakukan untuk melihat ketepatan adaptasi koping dengan preparasi serta memastikan ruang yang tersedia untuk porselen adekuat.

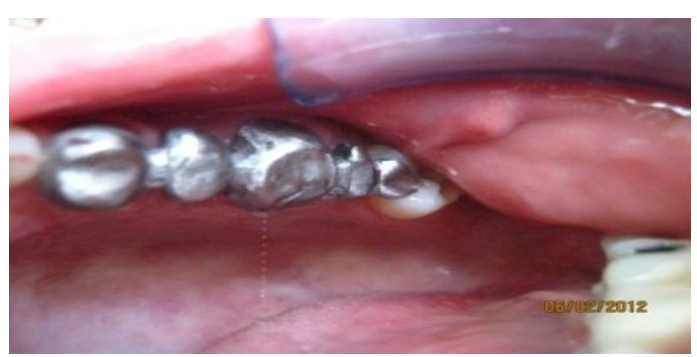

Gambar 4. Uji coba koping logam

Sebelum tahap sementasi, dilakukan ujicoba jembatan metal porselen dalam mulut untuk melihat estetik, adaptasi tepi retainer terhadap akhiran preparasi, adaptasi akhiran pontik terhadap gusi linggir, titik kontak dengan gigi sebelah serta kontak saat oklusi dan artikulasi. Sementasi dilakukan dengan menggunakan semen resin adhesive. Instruksi pasca insersi dijelaskan pada pasien untuk pemeliharaan kebersihan mulut pasien. Pada tahap kontrol tidak terdapat adanya impaksi makanan dan peradangan di sekitar jembatan.

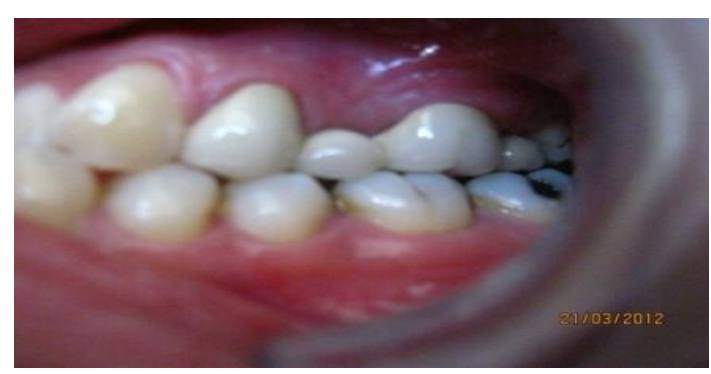

Gambar 5. Jembatan metal porselen setelah diinsersi

\section{PEMBAHASAN}

Tujuan utama perawatan prostodonsia adalah mengembalikan pasien pada keadaan dan fungsi yang normal. Pada kasus ini, pasien menginginkan dibuatkan gigi tiruan yang cekat agar fungsi pengunyahannya dapat kembali normal. Dari hasil pemeriksaan klinis maupun radiografis diketahui terdapat beberapa masalah yang harus diperhatikan yaitu terdapat penyempitan ruangan karena migrasi gigi sebelahnya. Disamping itu, ruang intermaksilaris pada regio 25 juga berkurang. 
Pemilihan full crown atau partial crown atau restorasi lain sebagai retainer pada jembatan posterior harus disesuaikan dengan keadaa $\mathrm{n}$ dalam mulut lain. ${ }^{9}$ Berdasarkan hukum Ante, kehilangan gigi 25 dan 27 pada kasus ini dapat diganti dengan jembatan yang disangga oleh gigi 24 dan 26 dengan major retainer berupa full crown PFM, serta inlay pada gigi 28 sebagai minor retainer. Disain fixed-moovable bridge ini dipilih karena terdapat pier abutment pada gigi 26 dan ruangan yang sempit pada regio 27. Fixed-movable bridge adalah jembatan yang memiliki rigid connector dan movable connector yang memungkinkan pergerakan vertikal yang minimal. Biasanya pada jembatan ini terdapat minor retainer berupa mahkota sebagian atau inlay. ${ }^{5,8,9}$

Penggunaan inlay sebagai retainer merupakan pilihan dalam pembuatan gigitiruan jembatan karena pembuangan jaringan gigi yang minimal, mudah menilai jaringan periodontal, dan relative lebih murah. Penelitian yang dilakukan oleh Al Moaleem mengevaluasi penggunaan porcelain fused to metalinlay retained bridge dalam periode waktu 3 tahun. Hasil penelitian ini menunjukkan hasil yang memuaskan karena semua masih berfungsi dengan baik dan tidak memerlukan perbaikan. ${ }^{10}$
Pontik yang digunakan pada gigi 25 adalah modified ridge lap dengan pertimbangan estetik karena gigi 25 terlihat saat pasien tersenyum. Untuk menggantikan gigi 27 yang hilang, digunakan pontik conical untuk memudahkan pasien dalam menjaga oral hygiene. Tetapi sayangnya, karena ruang intermaksilaris di regio 25 terlalu kecil, servical line pontik 25 dan 27 terletak lebih rendah dari gigi yang lainnya. Pasien menerima hal ini karena jika dibuatkan lebih panjang akan menyulitkan dalam membersihkan area di bawah pontik. Pontik modifikasi ridge lap menggabungkan sifat-sifat dari disain pontik sanitary dan ridge lap, yaitu menggabungkan antara estetika dan pembersihan yang mudah. Permukaan yang berbentuk ridge memberikan penampilan seolah-olah pontik muncul dari gingiva, sedangkan permukaan palatal berbentuk ovoid memungkinkan kontrol plak yang optimal. ${ }^{4}$

Disain substruktur yang tidak baik menyebabkan kegagalan restorasi metal keramik. Hal-hal yang mempengaruhi antara lain disain koping metal harus memberikan ketebalan porselen yang uniform, margin dibuat shoulder atau chamfer atau butt joint, dan permukaan koping logam yang menghadap porselen harus membulat tidak boleh ada sudut 
yang tajam untuk mencegah potensi titik keretakan yang akan memicu terjadinya fraktur jika ada stress pada daerah tersebut. $^{5-9}$

Jika koping metal terlalu tipis (kurang dari 0,4 mm), porselen akan mengalami shringkage sehingga menyebabkan distorsi pada koping logam. Ketebalan koping metal di daerah insisal yang tidak cukup akan mengakibatkan deformasi metal dibawah stress mastikasi. Oleh karena itu, pencakupan metal di insisal dan di lingual harus cukup tebal dan luas. ${ }^{4}$

\section{SIMPULAN}

Gigitiruan jembatan metal
porselen merupakan pilihan untuk
mengganti beberapa gigi posterior yang
hilang. Keberhasilan perawatan dengan
gigitiruan ini membutuhkan pemilihan
kasus yang selektif, perencanaan desain
tepat, dan prosedur perawatan yang
benar. Ketahanan gigitiruan juga
didukung kemampuan dan kemauan
pasien untuk menjaga kebersihan
mulutnya.

\section{KEPUSTAKAAN}

1. Binobaid A. A novel dental bridge design. Thesis. University Of Manchester. 2012

2. Carr. AB, McGivney. GP, Brown. DT. McCracken's Removable partial prosthodontics. Ed 11. 2005. Mosby. St. Louis.

3. Love WD, Adams RL. Tooth movement into edentulous areas. J Prosth Dent 1971; 25: 271-277. In Hemming K, Harrington Z. Replacement of Missing Teeth with Fixed Prostheses. Dent update. April. 2004

4. Motta AB, Pereira LC, Da Cunhaa Ar. Allceramic and porcelain-fused-to-metal Fixed partial dentures: a comparative study by $2 \mathrm{~d}$ finite element analyses. J Appl Oral Sci. 2007;15(5):399-405

5. Rosenstiel SF, Land MF, Fujimoto J. Contemporary fixed prosthodontic. $3^{\text {rd }}$ Ed. St. Louis. Mosby Inc: 2001; p. 216-220.

6. Goldstein R. Esthetics in dentistry. Vol. 1: Principles communication treatment methods. Hamilton: B.C. Decker Inc; 1998. p. $414-430$

7. Tian M, Sai Ma, Lina Niu, Jihua Chen. Gingival pigmentation by Ni-Cr-based metal ceramic crowns: A clinical report. J Prosth Dent. 2016; 115(1): 1-4

8. Zinner ID. Panno FV. Miller RD. et al. Ceramometal full coverage restoration. In: Aschheim KW. Dale BG.Ed. Esthetic dentistry: a clinical approach to techniques and materials. $2^{\text {nd }}$ ed. St.Louis: Mosby, Inc; 2001.p. 61-64, 114 - 134.

9. Smith BGN, Lowe LC. Planning and making crown and bridges

10. Al- Moaleem MM. Clinical Evaluation of Porcelain Fused to Metal Inlay-Retained Bridges. J Dent Med Scie .Volume 13, Issue 9 Ver. VI (Sep. 2014), pp. 129-133 